\title{
Laparoscopic Microwave Liver Ablation and Portal Vein Ligation: An Alternative Approach to the Conventional ALPPS Procedure in Hilar Cholangiocarcinoma
}

\author{
Ugo Boggi, MD, FEBS ${ }^{1}$, Niccolò Napoli, MD ${ }^{1}$, Emanuele F. Kauffmann, MD ${ }^{1}$, Giuseppe Lo Presti, Eng ${ }^{2}$, and \\ Andrea Moglia, $\mathbf{P h D}^{2}$ \\ ${ }^{1}$ Division of General and Transplant Surgery, Azienda Ospedaliera Universitaria Pisana, Università di Pisa, Pisa, Italy; \\ ${ }^{2}$ EndoCAS, Center for Computer-Assisted Surgery, University of Pisa, Pisa, Italy
}

\begin{abstract}
Background. Associating liver partition and portal vein ligation for staged hepatectomy (ALPPS) is a new procedure aimed at promoting the overgrowth of small future liver remnants (FLR). The role of ALPPS in hilar cholangiocarcinoma (h-CCA) is currently considered marginal because liver split in the presence of bile duct obstruction increases postoperative morbidity and mortality (Schadde et al. in Ann Surg 260:829-836, 2014; Nadalin et al. in Z Gastroenterol 52:35-42, 2014). Virtual liver split (Gall et al. in Ann Surg 261:e45-e46, 2015) could improve the outcome of ALPPS in h-CCA.

Methods. A 64-year-old woman with a type IIIA h-CCA without evidence of vascular involvement had a small FLR (FLR/body weight: $0.47 \mathrm{~cm}^{3} / \mathrm{kg}$ ). After bilateral percutaneous biliary drainage (PBD) and bilirubin normalization, the patient was planned for laparoscopic step 1 ALPPS using microwave ablation (MWA). Because of possible challenge in hilar dissection in this tumor type, robotic assistance was preferred to conventional laparoscopy for step 1.

Results. The patient recovered promptly from step 1, with a $68 \%$ increase in the volume of FLR by postoperative day (POD) 10 (FLR/body weight of $0.79 \mathrm{~cm}^{3} / \mathrm{kg}$ ). On POD 15 , the patient underwent open right hepatectomy with en bloc
\end{abstract}

Electronic supplementary material The online version of this article (doi:10.1245/s10434-016-5297-x) contains supplementary material, which is available to authorized users.

(C) Society of Surgical Oncology 2016

First Received: 26 February 2016;

Published Online: 8 June 2016

U. Boggi, MD, FEBS

e-mail: u.boggi@med.unipi.it resection of the caudate lobe, bile duct bifurcation, and extrahepatic biliary duct (T2N1M0R0). Estimated blood loss was negligible during step 1 and $150 \mathrm{~mL}$ during step 2. The patient recovered well. Chemotherapy was started 6 weeks after ALPPS stage 2, and was well tolerated and full course. Twenty months after resection the patient is alive, well, and disease-free.

Conclusions. Laparoscopic ALPPS (Machado et al. in Ann Surg 256:e13, 2012) and MWA on the intended split line (Gringeri and Boetto in Ann Surg 261:e42-e43, 2015) have been recently described. The combination of these techniques with PBD allowed successful ALPPS in a patient with h-CCA.

DISCLOSURES Ugo Boggi, Niccolò Napoli, Emanuele F. Kauffmann, Giuseppe Lo Presti, and Andrea Moglia have no conflicts of interest or financial ties to disclose.

\section{REFERENCES}

1. Schadde E, Ardiles V, Robles-Campos R, et al. Early survival and safety of ALPPS: first report of the International ALPPS Registry. Ann Surg. 2014;260:829-836.

2. Nadalin S, Capobianco I, Li J, Girotti P, Königsrainer I, Königsrainer A. Indications and limits for associating liver partition and portal vein ligation for staged hepatectomy (ALPPS). Lessons learned from 15 cases at a single centre. Z Gastroenterol. 2014;52:35-42.

3. Gall TM, Sodergren MH, Frampton AE, et al. Radio-frequencyassisted liver partition with portal vein ligation (RALPP) for liver regeneration. Ann Surg. 2015;261:e45-6.

4. Machado MA, Makdissi FF, Surjan RC. Totally laparoscopic ALPPS is feasible and may be worthwhile. Ann Surg. 2012;256:e13.

5. Gringeri E, Boetto R, DAmico FE, Bassi D, Cillo U. Laparoscopic microwave ablation and portal vein ligation for staged hepatectomy (LAPS): a minimally invasive first-step approach. Ann Surg. 2015;261:e42-43. 